\title{
Accounting for the distributional impacts of policy in the green accounts
}

\author{
RICHARD D. HORAN \\ Agricultural Economist, RED/ERS/USDA, Room 4015, 1800 M St., \\ Washington, D.C. 20036-5831, email: rhoran@econ.ag.gov \\ JAMES HRUBOVCAK \\ Agricultural Economist, RED/ERS/USDA, Room 4010, 1800 M St., \\ Washington, D.C. 20036-5831
}

\section{JAMES S. SHORTLE}

Professor, Department of Agricultural Economics, 112 Armsby Building, The Pennsylvania State University, University Park, PA 16802

\author{
ERWIN H. BULTE
}

Assistant Professor, Department of Economics, Tilburg University, P.O. Box 90153, 5000 LE Tilburg, The Netherlands

\begin{abstract}
Green income accounting models are designed to appropriately value changes in a country's natural resource (natural capital) base. However, green NNP is useful as a guide for domestic and international policy only to the extent that it accurately reflects the economic goals and policy options of policy makers. For example, international policy designed to slow natural capital depletion in a developing country is more effective if policy makers recognize the developing country's perceived income effects of the policy. Traditional green accounting models do not satisfy this criterion because they are based on the assumption that policy makers are either not concerned with the distributional consequences of policies, and/or are not limited in the instruments available to them. We present an alternative green NNP measure that reflects distributional goals and policy implementation. Using this measure, the depletion (accumulation) of natural capital stocks in excess of economically efficient rates may increase income.
\end{abstract}

\section{Introduction}

Traditional income accounting systems have been criticised in recent years because changes in a country's natural resource (natural capital) base are excluded from traditional NNP measures (see Mäler, 1991, or Hanley,

Thanks to two anonymous reviewers, the managing editor, and the editor for helpful comments. All remaining errors are our own. The views expressed in this paper are those of the authors and do not necessarily reflect those of the Economic Research Service or the USDA. 
Shogren and White, 1997). Indeed, there has been a growing interest in modifying traditional NNP measures to include changes in natural capital and environmental quality, thereby providing a more complete and accurate measure of social income and welfare (Hartwick, 1990; Mäler, 1991; Repetto, 1992). One goal of 'green $\mathrm{NNP}^{\prime}$ measures is to properly treat changes in natural capital so that green NNP is truly a measure of the maximum amount that could be consumed in one period without reducing consumption in future periods, or 'sustainable income' (Weitzman, 1997; Weitzman and Löfgren, 1997). Much of the recent economic 'green accounting' literature provides a conceptual framework for a sustainable income measure (e.g., Hartwick, 1990; Mäler, 1991; Weitzman, 1997). Following Aronsson and Löfgren (1995), we refer to the basic measure of sustainable income as the Weitzman-Hartwick-Mäler (W-H-M) measure (henceforth $N N P_{W-H-M}$ ).

There are two important potential limitations to $N N P_{W-H-M}$. The first limitation, which has been identified in previous literature (e.g., Hartwick, 1990; Dasgupta, 1993, 1997), relates to the fact that $N N P_{W-H-M}$ is derived under the assumption that an economy's consumption and investment decisions follow an economically efficient path. However, natural resources are most often allocated inefficiently and externalities are not fully corrected. This is especially true in developing countries (Dasgupta, 1997, 1993). Market data on consumption levels, prices, and changes in capital and natural capital stocks will differ from their counterparts in $N N P_{W-H-M}$ because the decisions made along an economically inefficient path are not equivalent to those that would be made along an economically efficient path (Hrubovcak, Le Blanc and Eakin, 1995). ${ }^{1}$ In addition, shadow values of changes in capital and natural capital that are measured using market data will be biased (Dasgupta, 1993).

The second potential limitation of $N N P_{W-H-M}$ relates to its effectiveness as a tool for assessing economic performance and guiding policy choices when policy makers have distributional goals and/or limited policy options. Green NNP is useful as a performance measure and a guide for domestic and international policy only to the extent that it accurately reflects policy makers' goals and policy options. However, $N N P_{W-H-M}$ is limited in that the assumptions underlying its derivation presuppose that economic efficiency is the goal of policy makers. Under the assumption of economic efficiency, public policies to modify resource use are warranted when imperfect or missing markets cause a loss of social economic value relative to the allocation that maximises the net present value of economic benefits accruing to society as a whole. These benefits include scarcity rent due to the resource, consumers' surplus, and rents for factors of production that are not supplied at a constant cost to the resource industry (with exogenous prices for inputs and outputs, this amounts to maximising rent to the industry) (see, e.g., Freeman, 1993; Clark, 1990; Conrad, 1995).

Economic efficiency is consistent with the maximisation of social welfare

${ }^{1}$ In the presence of externalities, $N N P_{W-H-M}$ is an economically efficient benchmark income level that can only be measured using bioeconomic modelling and/or other simulation methods. 
when the public sector uses non-distortionary policies (i.e., lump sum transfers) to adjust income distributions. However, contemporary welfare economics (e.g., the 'New New Welfare Economics') rejects the feasibility of non-distortionary inter- and intra-generational transfers to achieve distributional objectives, and suggests that both efficiency and distributional effects should be considered in optimal policy design (see, e.g., Feldstein, 1972; Stiglitz, 1987; Gardner, 1987b). In a related but somewhat different vein, public choice theory and applied research suggest economic efficiency is not a major consideration in actual resource policy. Instead, policy makers seem to be particularly concerned with the economic welfare of politically powerful interest groups with a direct economic interest in the use of resources and equity issues (e.g., Mueller, 1989; Hahn, 1990; Gardner, 1987b; Holden, 1994; Anderson, 1984; Coull, 1993; Clark, 1985; Hartwick and Olewiler, 1986; Coates, 1996; and Rausser and Foster, 1991). ${ }^{2}$ This may be especially true in many developing countries where interest groups heavily influence government policies, creating incentives (e.g., through income redistribution) for farmers to deplete natural capital stocks (Dasgupta, 1997, 1993). Indeed, although applied literature suggests economic growth in many developing countries is not sustainable in terms of the natural resource base (Repetto et al., 1989; Pearce and Atkinson, 1995), policies often lead to environmental degradation and natural resource depletion (Dasgupta, 1993). It is therefore realistic to assume policies are designed to allocate resources within the context of policy makers' preferences over politically valued groups, not to maximise aggregate economic surplus. ${ }^{3}$

In this paper, we develop a measure of green NNP that accounts for changes in natural capital and incorporates the distributional goals of policy makers. Specifically, policy makers are assumed to be concerned about the distribution of economic welfare among groups within society, as well as the total social surplus. Following economic literature on regulation in other sectors (e.g., Gardner, 1987b; Rausser, Lichtemberg and Lattimore, 1982; Peltzman, 1976; and Becker, 1974), we assume policy makers seek to maximise a political preference function defined over the economic surplus that accrues to the politically valued groups. The underlying argument is that the agency's preferences are an equilibrium outcome of the interaction of interest groups and political decision makers in political markets (Mueller, 1986). The NNP measure derived under this approach will be appropriate to gauge performance and guide policy

2 Policy makers' concerns with the distributional impacts of policies have also been recognised and studied in other sectors such as agriculture (Gardner, 1987a; Oehmke and Yao, 1990; Shortle and Laughland, 1994) and electric utilities (Nelson and Roberts, 1989).

${ }^{3}$ Rausser (1982) describes resource policies as political economic resource transactions policies (PERTs) or political economic-seeking transfer policies (PESTs) according to whether they are intended to enhance efficiency by addressing market failures (PERTs) or to enhance the welfare of particular interest groups (PESTs). In general, resource policies will contain aspects of both PERTs and PESTs, where 'PERTs expand the size of the pie, and PESTs allocate the portions served' (Rausser and Foster, 1990). 
because it incorporates the actual shadow values that society, as a result of public intervention, places on reproducible and natural capital.

\section{The model}

\subsection{The economy}

Consider an economy that produces a single composite good, $Y$, according to the concave production function $f(\alpha K, \beta L, h)\left(f_{i}>0, i=K, L, h\right)$, where $K$ is aggregate reproducible capital (henceforth, capital), $L$ is aggregate labour, $\alpha<1$ and $\beta<1$ are, respectively, the proportions of $K$ and $L$ used in the production of $Y$ and $h$ is a natural resource commodity. ${ }^{4}$ Total production, $f$, can either be sold for consumption, $C$, or invested, $I$, into the capital stock

$$
f(\alpha K, \beta L, h)=C+I .
$$

The capital stock evolves over time according to the equation of motion $\dot{K}=I-\delta K$, where $\delta$ is the depreciation rate of capital. Using (1), the equation of motion for capital accumulation can be written as

$$
\dot{K}=f(\alpha K, \beta L, h)-C-\delta K .
$$

Natural capital, denoted $X$, is harvested by a competitive resource industry, which has open access to the resource stock. Such an industry would harvest the resource inefficiently in the absence of public intervention to correct the market failure. Harvesting of the natural resource occurs according to the concave production function $h([1-\alpha] K,[1-\beta] L, X)\left(h_{i}>\right.$ $0, i=K, L, X)$. For simplicity, it is assumed that labour for each production activity is hired from the same market. The natural capital stock evolves according to the equation of motion

$$
\dot{X}=g(X)-h,
$$

where $g(X)\left(g^{\prime \prime}<0, g(0)=g(\bar{X})=0\right.$, where $\bar{X}$ is the largest resource stock level that can be sustained naturally by the ecosystem, i.e., the carrying capacity) describes the natural reproduction of $X(g(X)=0 \forall X$ in the case of a non-renewable resource).

\subsection{Social welfare and public policy goals}

Consider a social planner (e.g., a government) who values differently the economic welfare of various groups with an economic interest in the production of the consumption good, and whose preferences are manifested through social policy choices. Assuming lump sum transfers can be used to costlessly redistribute income, a fundamental result of welfare economics is that a social preference function, defined over the utility of all agents in the economy (or, equivalently, aggregate economic surplus), is maximised by choosing policy instruments to obtain a Pareto optimum and using lump sum transfers to optimally redistribute income (Blanchard and Fischer, 1993; Gardner, 1987b; Atkinson and Stiglitz, 1980; Starrett, 1989). However, lump sum transfers often have practical limitations (e.g., some redistributions may involve welfare from future to current gener-

${ }^{4}$ Alphabetical subscripts denote partial derivatives. For example, $f_{L}=\partial f / \partial L$. 
ations) and are typically passed up in favour of policies with more direct market intervention. Without lump sum transfers, solutions to traditional accounting models founded on utility-based social welfare functions may be unattainable.

Blanchard and Fischer (1993) suggest a more realistic and appropriate objective function would be defined directly over relevant macroeconomic variables, or aggregate market-based measures of economic welfare. Such a function, which they refer to as a macro welfare function, is more representative of how policies are actually made. In keeping with the public choice literature, we adopt the term political preference function (PPF) (Rausser and Foster, 1990). ${ }^{5}$

For simplicity, assume preferences are defined over three groups: consumers, firms and labour. This choice of groups is consistent with the political preference approach because these groups correspond to those that often influence natural resource policy (e.g., Holden, 1994; Anderson, 1984; Coull, 1993; Clark, 1985, and Hartwick and Olewiler, 1986; Coates, 1996; and Rausser and Foster, 1991). The economic welfare measures associated with these groups are consumers' surplus $\left(C S=\int_{0}^{C} p(v) d v-\right.$ $p(C) C)$, firms quasi-rents $(P S=p(C) C-w(L) L)$ and labour rents $(L R=$ $\left.w(L) L-\int_{0}^{L} w(v) d v\right)$, where $p(C)\left(p_{c}<0\right)$ denotes inverse demand for the consumption good and $w(L)\left(w_{L}>0\right)$ denotes inverse labour supply. ${ }^{6}$ The PPF defined over these welfare measures is written as $W(C S, P S, L R)\left(W_{i}>0\right.$, $i=C S, P S, L R)$ and is assumed to be strictly quasi-concave. ${ }^{7}$ This PPF is general enough to encompass both the economic goals of policy makers and the manner in which policies are implemented (e.g., direct market intervention or lump sum transfers). Therefore, this framework can be

${ }^{5}$ Public choice models can be broadly defined as either voting models or interest group models. Interest group models include models with an influence function, composite utility models and campaign contribution models (Potters and van Winden, 1996). The composite utility (i.e., PPF) approach is used here because of its relative simplicity and because it is best suited for the objectives of this study. This approach is based on the assumption that the planner's preferences reflect the outcome of the interplay of interest groups in political-economic markets. The interplay of agents is not modelled explicitly. The explicit modelling of strategic behaviour, while important, will only serve to complicate the model and draw attention away from the main focus which is to look at the impact of political preferences on resource policy. Instead, the PPF acts as a black box and serves as the planner's objective function when choosing policies.

${ }^{6}$ For simplicity, demand for the consumption good and labour supply are taken to be Marshallian for use as welfare approximations. Welfare is more accurately measured with Hicksian demand and supply relationships. The use of Marshallian relationships greatly simplifies the analysis without a great loss in generality.

7 This is but one possible specification for the PPF. The number of possible objectives is extreme and may be quantitative (e.g., income and employment levels, existence values), or qualitative in nature (e.g., traditions, cultural values, etc.). We focus on the elements comprising economic surplus because of the economic interest associated with these welfare measures. In addition, this specification allows for comparison of our results with previous work that only focuses on economic efficiency as the goal of the planner. 
used to derive a measure of NNP that is consistent with policy goals and implementation, while also consistent with applied welfare economics.

\section{The command optimum}

We focus on a 'command optimum', noting that the planner has access to a variety of policy instruments to attain this optimum. ${ }^{8}$ The planner's problem is to choose values of $C, L, \alpha$ and $\beta$ to maximise discounted social welfare over time, subject to the capital and natural capital equations of motion

$$
\begin{gathered}
\operatorname{Max}_{L, I, \alpha, \beta} \int_{0}^{\infty} W(C S, P S, L R) e^{-r t} d t \\
\text { s.t. (2), (3), } \\
L \leqslant T
\end{gathered}
$$

where $r$ denotes the social rate of time preference and $T$ is the total time available to work in the economy ( $T-L$ equals leisure). The current value Hamiltonian for this problem is

$$
\begin{gathered}
H=W(C S, P S, L R)+\lambda_{1}[f(\alpha K, \beta L, h)-C-\delta K] \\
+\lambda_{2}[g(X)-h([1-\alpha] K,[1-\beta] L, X)]+\lambda_{3}[T-L],
\end{gathered}
$$

where $\lambda_{1}$ and $\lambda_{2}$ are the costate variables for $K$ and $X$, respectively, and $\lambda_{3}$ is a Lagrangian multiplier for the labour constraint. The necessary conditions for an interior solution are

$$
\begin{gathered}
\frac{\partial H}{\partial C}=\left[W_{C S}-W_{P S}\right]\left[-p_{C} C\right]+W_{P S} p-\lambda_{1}=0 \\
\frac{\partial H}{\partial L}=-W_{P S} w+\left[W_{L R}-W_{P S}\right] w_{L} L+\lambda_{1}\left[f_{L} \beta+f_{h} h_{L}(1-\beta)\right] \\
-\lambda_{2} h_{L}[1-\beta]-\lambda_{3}=0 \\
\frac{\partial H}{\partial \alpha}=\lambda_{1}\left[f_{K} K-f_{h} h_{K} K\right]+\lambda_{2} h_{K} K=0 \\
\frac{\partial H}{\partial \beta}=\lambda_{1}\left[f_{L} L-f_{h} h_{L} L\right]+\lambda_{2} h_{L} L=0 \\
\dot{\lambda}_{1}=r \lambda_{1}-\lambda_{1}\left[f_{K} \alpha+f_{h} h_{K}(1-\alpha)-\delta\right]+\lambda_{2} h_{K}(1-\alpha) \\
\dot{\lambda}_{2}=r \lambda_{2}-\lambda_{1} f_{h} h_{X}-\lambda_{2}\left(g_{X}-h_{X}\right) \\
T-L \geqslant 0 ; \lambda_{3}[T-L]=0
\end{gathered}
$$

and the equations of motion (2)-(3) along with the appropriate non-nega-

\footnotetext{
${ }^{8}$ We focus on the command optimum for convenience due to the large number of instruments available to the planner. Note that many policies involve transfer payments. In a decentralised optimum, the planner may evaluate changes in its budget according to the effects on tax payers, with transfer payments modelled as a fourth argument in the PPF. When policies are chosen optimally, the solution will be the same (see Horan, Shortle and Bulte, 1999).
} 
tive and transversality conditions. ${ }^{9}$ For simplicity, it is assumed that $L<T$ (i.e., leisure is consumed at positive levels) and thus $\lambda_{3}=0$. The solution of (2)-(10) along with the other appropriate conditions yields a politically efficient path for all variables, $C^{*}(t), L^{*}(t), \alpha^{*}(t), \beta^{*}(t), K^{*}(t), X^{*}(t), \lambda_{1}^{*}(t)$ and $\lambda_{2}{ }^{*}(t)$. The politically efficient values of the PPF and the Hamiltonian are denoted $W^{*}(t)$ and $H^{*}(t)$, respectively.

Conditions (4)-(9) reveal several distributional tradeoffs facing the planner. Equation (4) requires aggregate consumption to occur such that the marginal political net benefit of additional consumption (the first two terms) equals the marginal political opportunity cost of the additional consumption, $\lambda_{1}$. The first term, $\left[W_{C S}-W_{P S}\right]\left[-p_{C} C\right]$, is the political value of the price reduction induced by additional consumption. Consumers benefit from reduced prices while producers are made worse off. Therefore, the willingness of the planner to pursue increased aggregate consumption depends, in part, on the relative marginal political utility of consumers and producers (i.e., $W_{C S}-W_{P S}$ ). The second term, $W_{P S} p$, is the additional revenue received by producers from a marginal increase in sales, weighted by the marginal political utility for firms.

Equation (5) describes the political tradeoffs that occur from a marginal increase in aggregate employment levels. The first term, $-W_{P S} w$, is the political value of the additional wages paid by producers from a marginal increase in employment. The second term, $\left[W_{L R}-W_{P S}\right] w_{L} L$, is the political value of the wage increase induced by additional employment. Labour benefits from increased wages while producers are made worse off. The last two terms, $\lambda_{1}\left[f_{L} \beta+f_{h} h_{L}(1-\beta)\right]-\lambda_{2} h_{L}[1-\beta]\left(\right.$ since $\lambda_{3}=0$ ), reflect the marginal political net benefits of increased production in each market due to an increase in aggregate employment.

In equilibrium, equations (6) and (7) require that the political (and real) long- and short-run marginal resource harvesting costs are equated, i.e., that $\lambda_{1} f_{L} / h_{L}=\lambda_{1} f_{K} / h_{K}$. Manipulating either (6) or (7) leads to the following condition

$$
\lambda_{1}\left[f_{h}-\frac{f_{L}}{h_{L}}\right]=\lambda_{2}
$$

Condition (11) requires that the political marginal rents from resource harvesting activities (the LHS) equal the political marginal user cost of the resource, $\lambda_{2}$.

Finally, conditions (8) and (9) are standard capital and natural capital stock arbitrage conditions, in terms of political utility. Analogous conditions have been discussed at length elsewhere (see Clark, 1990).

The solution to the necessary conditions (4)-(9) will only be economically efficient (i.e., aggregate economic surplus will be maximised) for the special case in which $W$ is linear with constant and equal weights (i.e., the

9 The second-order conditions are assumed to be satisfied at the optimum. This may not always be the case. The policy implications resulting from an agency with a PPF for which the second-order conditions are not satisfied, while interesting, are not discussed here. 
terms $W_{i}(i=C S, P S, L R)$ are constant $\forall t$ and $\left.W_{C S}=W_{P S}=W_{L R}\right)$. Under these conditions (4)-(7) simplify to

$$
\begin{gathered}
p=\lambda_{1}^{\prime} \\
f_{L}=\frac{w}{p} \\
p\left[f_{h}-\frac{f_{L}}{h_{L}}\right]=\lambda_{2}^{\prime}
\end{gathered}
$$

where $\lambda_{i}^{\prime}=\lambda_{i} / W_{P S}(i=1,2)$. Equations (12) and (13) are standard efficiency conditions and require no further explanation. In (14), the derived price for the resource commodity is $p f_{h^{\prime}}$ and the marginal resource harvesting cost is $p f_{L} / h_{L}=p f_{K} / h_{K}$. Thus, (14) is the standard efficiency condition that equates the shadow value of the resource with the marginal rents from harvesting (Clark, 1990), In general, comparisons between the economically efficient and politically efficient outcomes cannot be made without further restrictions on the model.

\section{Green NNP}

Unlike traditional models in which a linearised transformation of the Hamiltonian equals $N N P_{W-H-M^{\prime}} H^{*}(t)$ is not easily transformed to become a measure of green NNP. ${ }^{10}$ Instead, following Weitzman (1976) and Aronsson and Löfgren (1998), it is straightforward to show that $r V^{*}(t)=$ $H^{*}(t)$, where

$$
V^{*}(t)=\int_{t}^{\infty} W^{*}(s) e^{-r(s-t)} d t
$$

Thus, $H^{*}(t)$ is the maximum amount of politically weighted economic surplus that can be obtained at any point in time while leaving total political utility constant.

A measure of green NNP that reflects the distributional goals of policy makers, denoted Political NNP or $N N P_{p}$, can be derived from $H^{*}(t)$. Nominal $N N P_{P}$ is the value of consumption, $p C$, plus the value of leisure, $w l$ (where $l$ is leisure), plus the value that society applies to net (natural and reproducible) capital investment (Mäler, 1991; Dasgupta, 1993). It is possible to obtain this value of net investment from $H^{*}(t)$. Following a line of reasoning similar to that of Hamilton (1996), the shadow values $\lambda_{i}(i=1,2)$ represent the political value of net investment. These political values can be transformed to monetary values through an appropriate normalisation procedure. Because the economically efficient solution is a special case of our model, it is clear from (12) and (14) that the appropriate transformation involves normalising each shadow value by the optimal marginal political utility of firms, $W_{P S}^{*}$. Then, nominal $N N P_{P}$ is

$$
\text { Nominal } N N P_{P}=p C+w l+\lambda_{1}^{\prime} \dot{K}+\lambda_{2}^{\prime} \dot{X}
$$

Real $N N P_{P^{\prime}}$, or just $N N P_{P^{\prime}}$ is obtained by normalising by the price level, $p$

$$
N N P_{P}=C+(w / p) l+\left(\lambda_{1}^{\prime} / p\right) \dot{K}+\left(\lambda_{2}^{\prime} / p\right) \dot{X}
$$


The formula for $N N P_{P}$ in (15) is the same as formulas derived in traditional green accounting models (see, e.g., Mäler, 1991; Dasgupta, 1993; or note 10), with the exception of the shadow values of $\dot{K}$ and $\dot{X}$ (which reflect the distributional goals of policy makers). This is as expected since the economically efficient solution is a special case of our model, implying that $N N P_{W-H-M}$ is a special case of $N N P_{P}$. Except for this special case, however, $N N P_{P}$ differs from $N N P_{W-H-M}$ in that $N N P_{P}$ is not the maximum amount of production that can be consumed at any point in time while leaving total wealth constant. This difference is due to the presence of distortions in the economy.

There are two possible interpretations for the PPF and hence $N N P_{P}$. The first interpretation is that the planner's preferences are actually defined by the PPF, with the corresponding measure of $N N P_{P}$ defined as politically efficient income, or $N N P_{P E}$. $N N P_{P E}$ may not be accurately reflected by market data if there are limits on the planner's ability to maximise the PPF. The second interpretation is that observed policies and outcomes are consistent with the maximisation of such a function (i.e., a revealed preference approach; see, e.g., Rausser and Foster, 1991). In this case, the optimal values of $\lambda_{1}^{\prime}$ and $\lambda_{2}^{\prime}$ are the normalised values the planner actually applies to changes in the capital and natural capital stocks, whether or not an economically or politically efficient outcome is the result. Denote this measure of $N N P_{P}$ as actual political income, or $N N P_{P A}$, because it reflects the actual (real and shadow) values applied in the market. $N N P_{P A}$ is consistent with the philosophy that income is an ex post measure based on actual outcomes. The two interpretations coincide for the special case in which actual outcomes are politically efficient.

\subsection{Interpretation of shadow values}

Insights into the differences between $N N P_{P}$ and $N N P_{W-H-M}$ are obtained by examining the normalised political shadow values. The normalised shadow value $\lambda_{1}^{\prime}$ is derived from equation (4)

$$
\lambda_{1}^{\prime}=\left[1-e_{P S, C S} \in_{D}\right] p,
$$

where $e_{P S, C S}=\left(W_{C S} / W_{P S}\right)-1$, and $\epsilon_{D}<0$ is the inverse elasticity of demand. The term $e_{P S, C S}$ is defined as the marginal political preference for consumers relative to producers (with respect to the intra-generational distribution of income). There is a marginal political preference for consumers relative to producers when $e_{P S, C S}>0$, a relative marginal political preference for producers relative to consumers when $e_{P S, C S}<0$, and a neutral marginal political preference when $e_{P S, C S}=0$.

As noted above, an economically efficient solution corresponds to the planner having neutral marginal political preferences (i.e., it places equal

${ }^{10} N N P_{W-H-M}$ is derived from the current value Hamiltonian corresponding to the maximisation of $\int_{0}^{\infty} U(C, l) e^{-r t} d t$ subject to (2) and (3) (where $l$ is leisure). Denote this Hamiltonian by $H_{W-H-M}=U+\Psi_{1} \dot{K}+\Psi_{2} \dot{X}$, where $\Psi_{i}$ is the $i$ th costate variable. Linearising $U$ (i.e., $U=U_{C} C+U_{l} l$ ) and dividing by the marginal utility of consumption, $U_{C^{\prime}}$, we have $N N P_{W-H-M}=H_{W-H-M} / U_{C}=C+w l+\left(\Psi_{1} / U_{C}\right)$ $\dot{K}+\left(\Psi_{2} / U_{C}\right) \dot{X}$. 
value on the welfare of all groups at the margin). In this case, $\lambda_{1}^{\prime}=p$, which corresponds to a competitive outcome and standard accounting models where the optimal shadow value of capital equals the marginal utility of consumption (i.e., the price of the consumption good) (Hartwick, 1990; Mäler, 1991). When $e_{P S, C S}=-1$, then the solution corresponds to a monopolistic outcome. Thus, the term $e_{P S, C S}$ can be viewed as a measure of the extent to which firms have obtained benefits analogous to market power as a result of the planner's preferences (i.e., similar to a Herfindahl index). ${ }^{11}$ Values within the interval $[-1,0]$ describe the degree of politically induced monopoly power.

The normalised shadow value $\lambda_{2}^{\prime}$ can be obtained from equations (11) and (16)

$$
\lambda_{2}^{\prime}=\left[1-e_{P S, C S} \in{ }_{D}\right] p\left[f_{h}-\frac{f_{L}}{h L}\right] .
$$

The normalised political marginal user cost (the LHS) equals the marginal rent from harvesting $\left(p f_{h}-p f_{L} / h_{L}\right)$, adjusted to reflect the political tradeoffs between producers and consumers $\left(1-e_{P S, C S} \in_{D}\right)$. Specifically, with more harvests, production of the consumption good increases. A marginal increase in production causes the price of $C$ to fall. Consumers benefit while producers are worse off from this lower price. However, producers benefit from the additional rents that come from increased production at the margin.

When $e_{P S, C S}=0$ (i.e., consumers and producers are valued equally at the margin), $\lambda_{2}^{\prime}$ equals the marginal rent from harvesting, just as in the economically efficient case (see, e.g., Hartwick, 1990). When $e_{P S, C S}=1 / \epsilon_{D^{\prime}}$ there is a marginal political preference for producers relative to consumers, and $\lambda_{2}^{\prime}=0$. This is similar to a situation of unregulated open access because no intertemporal costs are associated with resource harvesting. ${ }^{12}$ Therefore, in addition to being a measure of market power, values of $e_{P S, C S}$ $\in\left[1 / \epsilon_{D^{\prime}} 0\right]$ represent an index of the degree of economic efficiency associated with the management of the natural resource stock.

\subsection{Policy implications and comparison with alternative green NNP measures}

Green NNP is useful as a guide for domestic and international policy only to the extent that it accurately reflects the goals of policy makers. As suggested above, the relation between $N N P_{P}$ and $N N P_{W-H-M}$ is ambiguous without further specifying the model, regardless of which interpretation of $N N P_{P}$ is used. $N N P_{P}$ may be greater or lesser than $N N P_{W-H-M}$ depending on the structure of the PPF, production and harvesting technologies, and the structure of the final output and labour markets.

Even with further specification, however, comparison is likely to be prohibitive because $N N P_{W-H-M}\left(N N P_{P E}\right)$ is not consistent with market data

${ }^{11}$ See, e.g., Nelson and Roberts (1989) for a discussion of social preferences and market power, and Cowling and Waterson (1976) and Martin (1993) for discussions of market structure and indices of market power.

12 Unlike pure open access, it is not required that the marginal rents from harvesting be zero. Instead, they may be positive due to limited access as opposed to future considerations. 
when the actual decisions in an economy are not economically (politically) efficient. When market inefficiencies exist, Dasgupta (1993) proposes that NNP is appropriately specified by applying economically efficient prices and shadow values to actual production and consumption choices and actual changes in capital and natural capital. This income measure is consistent with the framework used to derive $N N P_{W-H-M^{\prime}}$ taking into account neither the political and institutional constraints facing policy makers, nor distributional considerations. In general, the relation between Dasgupta's measure and $N N P_{P A}$ (or a variant of $N N P_{P E}$ derived in a manner similar to Dasgupta's measure) is ambiguous without further specification of the model.

In practice, determining economically efficient prices and shadow values may be prohibitively difficult. Instead, actual prices are typically used as proxies for efficient prices. In addition, the actual price of the consumption good, $p$, and the actual marginal rents from resource harvesting, $\rho_{2}$, have been suggested for use as proxies for the economically efficient shadow values associated with the capital and natural capital stocks, respectively (Hartwick, 1990). This market-based measure of NNP, denoted $N N P_{M^{\prime}}$, has been used in practice (e.g., Hrubovcak, LeBlanc and Eakin, 1995; Crowards, 1995; Motta and May, 1996) to reflect the framework behind Dasgupta's income measure. ${ }^{13}$

In the context of the current model, $N N P_{M}$ is formally defined as (15) under the assumption that $e_{P S, C S}=0$. Clearly, $N N P_{M}$ will differ from $N N P_{P A}$ in most situations. This difference can be defined explicitly. Let $\rho_{1}$ be the measured shadow value of capital corresponding to $N N P_{M}$ (i.e., $\rho_{1}$ $=p$ ). The difference, $\Delta=N N P_{P A}-N N P_{M^{\prime}}$ is then defined as

$$
\Delta=\left[\lambda_{1}^{\prime}-\rho_{1}\right] \dot{K}+\left[\lambda_{2}^{\prime}-\rho_{2}\right] \dot{X}
$$

which simplifies to

$$
\Delta=\Theta\left[\rho_{1} \dot{K}+\rho_{2} \dot{X}\right],
$$

where $\Theta=-e_{P S, C S} \in_{D}$. The only instances in which $N N P_{P A}$ and $N N P_{M}$ will be equivalent are in the steady state, when there is no appreciation or depreciation of (natural) capital, or when the actual allocation is economically efficient, i.e., $N N P_{P}=N N P_{W-H-M}$. Apart from these special cases, $\Delta$ is diminished (but does not necessarily vanish) when there is unregulated open access harvesting of the resource stock. In this case, $\lambda_{2}^{\prime}=\rho_{2}=0$; however, it is not certain that $\lambda_{1}^{\prime}=\rho_{1}$ due to potential distortions in the capital market. $\Delta$ is

It is realistically expected that $\Theta<0$. Given this assumption, the sign of

$$
\begin{aligned}
& \Delta>0 \text { if } \dot{K}, \dot{X}<0 \\
& \Delta<0 \text { if } \dot{K}, \dot{X}>0 \\
& \Delta\left\{\begin{array}{l}
>0 \\
<
\end{array} \text { if } \dot{K}<0, \dot{X}>0 \text { or } \dot{K}>0, \dot{X}<0 .\right.
\end{aligned}
$$

13 According to Dasgupta, Kriström and Mäler (1995), most empirical work on national accounts is somewhat ad hoc. 
Other things equal, $N N P_{P A}$ will be larger (smaller) than $N N P_{M}$ during periods of capital and natural capital stock depreciation (appreciation). However, the sign of $\Delta$ is ambiguous when capital and natural capital stocks move in opposite directions. The most likely case for many countries is $\dot{K}>0, \dot{X}<0$.

There are two important implications of this analysis. First, economies may be managed to deplete (or accumulate) their natural capital stocks because they may lead to increased political income $\left(N N P_{P}\right)$. However, depending on the structure of the preference function, production and harvesting technologies, and the structure of the final output and labour markets, political income may or may not be correlated with sustainable income measures. Indeed, sustainable income measures may provide no indication as to what a country perceives its actual income to be, and may therefore be of limited value in guiding policy choices.

\section{Conclusion}

In this paper, we have argued that political income may or may not be correlated with sustainable income measures. We recognise, however, that efficiency-based income measures are not without their place. Indeed, economic efficiency is an accepted and well-understood criterion and is invariant to alternative political regimes and institutional constraints. Multiple income measures may therefore be useful. Sustainable income (i.e., the Weitzman-Hartwick-Mäler measure of green NNP) is the income level that would be attained in an economically efficient economy. A second useful income measure is based on Dasgupta's (1993) recommendation of applying economically efficient shadow values to actual changes in capital and natural capital. Dasgupta's income measure, which values actual decisions with economically efficient (shadow) prices, can be used to evaluate an economy's performance relative to the economically efficient benchmark. A final valuable income measure is political NNP because it is based on actual political goals and policies. Together, political NNP and Dasgupta's measure provide a more complete picture of economic well-being and economic performance than could be provided by either when used separately. For example, these measures would be useful in explaining why actual choices are made even though they do not increase income as measured in the traditional sense. Moreover, when used together, political NNP and Dasgupta's income measure provide a useful guide for designing domestic and international macroeconomic policies to enhance economic development in third world countries.

\section{References}

Anderson, L.G. (1984), 'Uncertainty in the fisheries management process', Marine Resource Economics, 1: 77-87.

Aronsson, T. and K.-G. Löfgren (1995), 'National product related welfare measures in the presence of technological change: externalities and uncertainty', Environmental and Resource Economics, 5: 321-332.

Atkinson, J. and J. Stiglitz (1980), Lectures on Public Economics, New York: McGrawHill. 
Becker, G.S. (1974), 'A Theory of social interaction', Journal of Political Economy, 82: 1063-1093.

Blanchard, O.J. and S. Fischer (1993), Lectures on Macroeconomics, Cambridge, MA: MIT Press.

Clark, C.W. (1985), Bioeconomic Modelling and Fisheries Management, New York: John Wiley and Sons.

Clark, C.W. (1990), Mathematical Bioeconomics: The Optimal Management of Renewable Resources, New York: John Wiley and Sons.

Coates, D. (1996), 'Jobs vs. wilderness areas: the role of campaign contributions', in R. Congleton, ed., The Political Economy of Environmental Protection, Ann Arbor: University of Michigan Press.

Conrad, J.M. (1995), 'Bioeconomic models of the fisher', in D.W. Bromley, ed., The Handbook of Environmental Economics, New York: Blackwell Handbooks in Economics.

Coull, J.R. (1993), World Fisheries Resources, New York: Routledge.

Cowling, K. and M. Waterson (1976), 'Price-cost margins and market structure', Economica, 43: 267-272.

Crowards, T.M. (1996), 'Natural resource accounting: a case study of Zimbabwe', Environmental and Resource Economics, 7: 213-241.

Dasgupta, P. (1993), An Inquiry into Well-Being and Destitution, New York: Oxford University Press.

Dasgupta, P. (1997), 'Environmental and resource economics in the world of the poor', Internet Edition: Resources for the Future.

Dasgupta, P., Kristöm, and K.-G. Mäler (1995), 'Current issues in resource accounting', in P.-O. Johansson, Kristöm, and K.-G. Mäler, eds., Current Issues in Environmental Economics, Manchester: Manchester University Press.

Feldstein, M.S. (1972), 'Distributional equity and the optimal structure of public prices', American Economic Review, 62: 32-36.

Freeman, A.M. III (1993), The Measurement of Environmental and Resource Values: Theory and Method, Washington, DC: Resources for the Future.

Gardner, B.L. (1987a), 'Causes of US farm commodity programs', Journal of Political Economy, 95: 290-310.

Gardner, B.L. (1987b), The Economics of Agricultural Policies, New York: Macmillan Publishing.

Hahn, R.W. (1990), 'The political economy of environmental regulation: towards a unifying framework', Public Choice, 65: 21-47.

Hamilton, K. (1996), 'Pollution and pollution abatement in the national accounts', Journal of Income and Wealth, 42: 13-33.

Hanley, N., J.F. Shogren and B. White (1997), Environmental Economics: In Theory and Practice, New York: Cambridge University Press.

Hartwick, J.M. (1990), Natural resources, national accounting and economic depreciation', Journal of Public Economics, 43: 291-304.

Hartwick, J.M. and N. Olewiler (1986), The Economics of Natural Resource Use, New York: Harper and Row.

Holden, M. (1994), The Common Fisheries Policy: Origin, Evaluation and Future, Fishing News Books.

Horan, R.D., J.S. Shortle and E.H. Bulte (1999), 'Renewable resource policy when distributional impacts matter', Environmental and Resource Economies 14: 191-215.

Hrubovcak, J., M. LeBlanc and B.K. Eakin (1995), 'Accounting for the environment in agriculture', Washington, DC: Economic Research Service, USDA.

Mäler, K.-G. (1991), 'National accounts and environmental resources', Environmental and Resource Economics, 1: 1-15.

Martin, S. (1993), Advanced Industrial Economics, Cambridge: Blackwell Publishers. 
Motta, R.S. and P.H. May (1996), 'Measuring sustainable income: The cases of mineral and forest depletion in Brazil', in R.S. Motta and P.H. May, eds., Pricing the Planet: Economic Analysis for Sustainable Development, New York: Columbia University Press.

Mueller, D.C. (1989), Public Choice II, Cambridge: Cambridge University Press.

Nelson, J.P. and M.J. Roberts (1989), 'Ramsey numbers and the role of competing interest groups in electric utility regulation', Quarterly Review of Economics and Business, 29: 21-42.

Oehmke, J.F. and X. Yao (1990), 'A policy preference function for government intervention in the US wheat market', American Journal of Agricultural Economics, 72: 631-640.

Pearce, D.W. and G. Atkinson (1995), 'Measuring sustainable development', in D.W. Bromley, ed., The Handbook of Environmental Economics, Cambridge: Blackwell Publishers.

Peltzman, S. (1976), 'Towards a more general theory of regulation', Journal of Law and Economics, 19: 211-240.

Potters, J. and F. van Winden (1996), 'Models of interest groups: four different approaches', in N. Schofield, ed., Social Choice and the Political Economy.

Rausser, G.C. (1982), 'Political economic markets: PERTs and PESTs in food and agriculture', American Journal of Agricultural Economics, 64: 821-833.

Rausser, G.C. and W.E. Foster (1990), 'Political preference function and public policy reform', American Journal of Agricultural Economics, 72: 641-652.

Rausser, G.C. and W.E. Foster (1991), 'The evolution and coordination of US commodity and resource policies', in R.E. Just and N. Bockstael, eds., Commodity and Resource Policies in Agricultural Systems, Berlin: Springer-Verlag.

Rausser, G.C., E. Lichtemberg and R. Lattimore (1982), 'Developments in theory and empirical applications of endogenous government behavior', in G.C. Rausser, ed., New Directions in Econometric Modelling and Forecasting in US Agriculture, New York: North-Holland.

Repetto, R. (1992), 'Earth in the balance sheet: incorporating natural resources into national income accounts', Environment, 34: 13-45.

Repetto, R., W. Magrath, M. Wells, C. Beer, and F. Rossini (1989), Wasting Assets: Natural Resources in the National Accounts, Washington, DC: World Resources Institute.

Shortle, J.S. and A. Laughland (1994), 'Impacts of taxes to reduce agrichemical use when farm policy is endogenous', Journal of Agricultural Economics, 45: 3-14.

Starrett, D.A. (1998), Foundations of Public Economics, Cambridge: Cambridge University Press.

Stiglitz, J.E. (1987), 'Pareto efficient and optimal taxation and the new new welfare economics', in A.J. Auerbach and M. Feldstein, eds., Handbook of Public Economics, New York: North-Holland.

Weitzman, M.L. (1997), 'Sustainability and technical progress', Scandinavian Journal of Economics, 99: 1-13.

Weitzman, M.L. (1976), 'On the significance of net national product in a dynamic economy', Quarterly Journal of Economics, 90: 156-162.

Weitzman, M.L. and K.-G. Löfgren (1997), On the welfare significance of green accounting as taught by parable', Journal of Environmental Economics and Management, 32: 139-153. 